\title{
Assessment of occupational exposure to inorganic arsenic based on urinary concentrations and speciation of arsenic
}

\author{
J G Farmer, L R Johnson
}

\begin{abstract}
An analytical speciation method, capable of separating inorganic arsenic (As (V), As (III)) and its methylated metabolites (MMAA, DMAA) from common, inert, dietary organoarsenicals, was applied to the determination of arsenic in urine from a variety of workers occupationally exposed to inorganic arsenic compounds. Mean urinary arsenic (As (V) + As (III) + MMAA + DMAA) concentrations ranged from $4.4 \mu \mathrm{g} / \mathrm{g}$ creatinine for controls to $<10 \mu \mathrm{g} / \mathrm{g}$ for those in the electronics industry, $47.9 \mu \mathrm{g} / \mathrm{g}$ for timber treatment workers applying arsenical wood preservatives, $79.4 \mu \mathrm{g} / \mathrm{g}$ for a group of glassworkers using arsenic trioxide, and $245 \mu \mathrm{g} / \mathrm{g}$ for chemical workers engaged in manufacturing and handling inorganic arsenicals. The maximum recorded concentration was 956 $\mu \mathrm{g} / \mathrm{g}$. For the most exposed groups, the ranges in the average urinary arsenic speciation pattern were $1-6 \%$ As (V), $11-14 \%$ As (III), 14 $18 \%$ MMAA, and $63-70 \%$ DMAA. The highly raised urinary arsenic concentrations for the chemical workers, in particular, and some glassworkers are shown to correspond to possible atmospheric concentrations in the workplace and intakes in excess of, or close to, recommended and statutory limits and those associated with inorganic arsenic related diseases.
\end{abstract}

Long term occupational exposure to inorganic arsenic compounds may lead to various diseases such as cancer of the respiratory tract, skin cancer,

Department of Forensic Medicine and Science, University of Glasgow, Glasgow G12 8QQ J G Farmer, L R Johnson

Present addresses: J G Farmer, Department of Chemistry, University of Edinburgh, West Mains Road, Edinburgh EH9 3JJ, and $L \mathrm{R}$ Johnson, Department of Biology, Memphis State University, Memphis, Tennessee 38152, USA. hyperkeratosis, hyperpigmentation, cardiovascular $\frac{\mathbb{D}}{3}$ disease, and disturbances of the peripheral vascular $\vec{t}$ and nervous systems. ${ }^{1-4}$ These chronic effects, while or different from those of acute arsenic intoxication, are $\omega$ similar to those resulting from long term environ- $N$ mental exposure of the general population in certain 윽 parts of the world to naturally raised inorganic arsenic concentrations in drinking water. ${ }^{1-4}$ Despite improved awareness and stricter legal requirements, there is still potential for occupational exposure to $\overrightarrow{0}$ inorganic arsenic in a range of industries, most $\stackrel{?}{?}$ notably non-ferrous smelting, glass making, and the manufacture and application of arsenical pesticides. Inhalation or ingestion of arsenic containing airborne dusts, or a combination of both, are two of the most important exposure pathways.

Assessment of exposure to airborne arsenic by direct atmospheric measurements alone is imprecise and unreliable. Biological markers are inherently more satisfactory as indicators of exposure. ${ }^{56} \mathrm{Hair}$, which has proved successful in forensic investigations of deliberate acute arsenic poisoning, ${ }^{1}$ is of ${ }^{\circ}$ rather less value in studies of occupational exposure, ? however, because of the problem of external contamination. Urine, more conveniently collected than blood, is the preferred indicator as excretion via the kidneys is the major route of elimination of inorganic arsenic (pentavalent, As (V); trivalent, As 은 (III)) and its metabolites (monomethylarsonic acid, $D$ MMAA, $\mathrm{CH}_{3} \mathrm{AsO}(\mathrm{OH})_{2}$; dimethylarsinic acid, 을. DMAA, $\left(\mathrm{CH}_{3}\right)_{2} \mathrm{AsO}(\mathrm{OH})$ ) from the human body. ${ }^{27-9} \mathrm{~N}$ It is extremely important that the analytical method used is capable of distinguishing these forms, separately or in toto, from the more complex but $\underset{\omega}{N}$ non-toxic organoarsenicals, such as arsenobetaine $\left(\left(\mathrm{CH}_{3}\right)_{3} \mathrm{As}^{+} \mathrm{CH}_{2} \mathrm{COOH}\right)$, whose presence in seafood 0 constitutes the major source of dietary arsenic. ${ }^{10} \stackrel{\overparen{D}}{\overparen{D}}$ Consumption of a meal of fish or shellfish can raise $\stackrel{\oplus}{?}$ urinary arsenic to concentrations in excess of $T$ $500 \mu \mathrm{g} / 1$, more than 50 times the typical background level. ${ }^{1112}$ Some studies of occupational, environmental, and dietary exposure to arsenic have overlooked or made insufficient allowance for this important effect. ${ }^{13}$

The initial purpose of this study was to establish the concentration and speciation of arsenic in urine 
from United Kingdom workers from a range of occupations subject to varying degrees and types of exposure to inorganic arsenic and to compare the results with control group data. Thereafter, the calculated intakes of inorganic arsenic, based partly on the measured urinary arsenic concentrations, could be compared with recommended limits and the doses associated with inorganic arsenic related ill health.

\section{Materials and methods}

Urine samples (first void or spot) were provided by a selected number of individuals working within the following occupational groups:

Semiconductor industry where arsenic is used as arsine gas in the doping of chips to enhance the conduction of the silicon or germanium crystal. Operators may be exposed to minute quantities of arsenic trioxide through the handling of the wafers ${ }^{14}$ but those more at risk are engaged in plant cleaning and maintenance ( $\mathrm{n}=14$; first void).

University electronics research group engaged in manufacturing gallium arsenide semiconductors, with potential for exposure to arsenic trioxide when cleaning out equipment ( $\mathrm{n}=7$; first void).

Glass manufacturing industry where arsenic trioxide is used as a decolourising agent in the manufacture of specialist glass. Possible exposure to airborne arsenic trioxide may occur during the weighing out of the constituents for each batch of glass and during the mixing of the chemicals ( $\mathrm{n}=30$; first void 18 , spot 12).

Timber treatment firm where pentavalent inorganic arsenic is used in combination with chromium and copper to prevent wood decay. Exposure is to airborne pentavalent inorganic arsenic during the mixing of the chemicals and via possible skin contact in handling the dried wood after treatment and removal from the solution. Again, exposure may be enhanced during the cleaning of equipment, in this case the tanks used to contain the wood preservative ( $\mathrm{n}=5$; first void).

Chemical firm engaged in manufacturing arsenic containing compounds. For plant operators, there is the possibility of exposure to $(a)$ arsenic trioxide as a result of dust escaping during the discharge of material into the reactor system and (b) arsenic pentoxide and sodium arsenate due to possible dust escaping during the filling of drums with the final product. Again, greater exposure may be experienced during maintenance work than normal production work. Urine samples were provided from those individuals thought to be subject to increased exposure $(n=24$; spot $)$.

Where possible, first void samples were collected in polypropylene bottles, preferably towards the end of the working week to allow the pattern of arsenic excretion to be established. Spot samples were collected when first void samples were not available. The samples were not subjected to any chemical pretreatment before storage under refrigeration at $4^{\circ} \mathrm{C}$ or $-20^{\circ} \mathrm{C}$ if longer storage periods were required.

In addition, first void urine samples were provided in the Glasgow area by 40 adults of the general population who were believed not to have been exposed to inorganic arsenic other than to the small amounts present in the typical United Kingdom diet. $^{10}{ }^{15} \mathrm{~A}$ further 28 spot urine samples from glassworkers were also provided by the Health and Safety Executive in London during an intercalibration exercise.

Individual arsenic species, As(V), As(III), MMAA, and DMAA, were separated from. a $4 \mathrm{ml}$ aliquot of each urine sample on a combined cation anion exchange resin column ${ }^{16}$ and determined by hydride generation atomic absorption spectrometry (HGAAS). ${ }^{15}$ The detection limit for each species in the original urine sample was $0.5 \mu \mathrm{g} / 1 .^{15}$ The total concentration of arsenic in each urine sample-that is, including any seafood organoarsenicals-was obtained by HGAAS after appropriate dilution of a nitric/sulphuric/perchloric acid digest. ${ }^{17} 18$

An intercomparison study, based on the analysis of urine samples supplied by the Health and Safety Executive in London, where analytical arsenic speciation is performed using a continuous HPLC/ HGAAS technique, ${ }^{19}$ showed good agreement in both speciation and total arsenic data. ${ }^{15} 18$ Additional confirmation of the latter was provided by accurate analysis of NBS freeze dried urine SRM 2670 $(480 \mu \mathrm{g} / \mathrm{l})$.

The fact that inorganic arsenic and its metabolites MMAA and DMAA may form hydrides directly from an acidified $(1.5 \% \mathrm{w} / \mathrm{v} \mathrm{HC1})$ sample solution, whereas the stable dietary organoarsenicals do not, afforded an opportunity for the rapid semiquantitative screening of urine samples to estimate the sum of the four species, As(V), As(III), MMAA, and DMAA. As a result of the differing rates of response of these species to hydride generation, ${ }^{20} 21$ the determination of a range of concentrations was all that could be achieved with the use here of signal peak heights. Peak areas may yield more precise estimates. ${ }^{22}$

Creatinine concentrations, necessary for the normalisation or correction of arsenic concentrations for fluctuations in urinary volume, were routinely determined, using an automatic method based on the Jaffe reaction, by the department of clinical biochemistry, Glasgow Royal Infirmary.

\section{Results}

Table 1 shows good agreement between the direct hydride generation range and the sum of hydride forming arsenic species' concentrations over a wide 


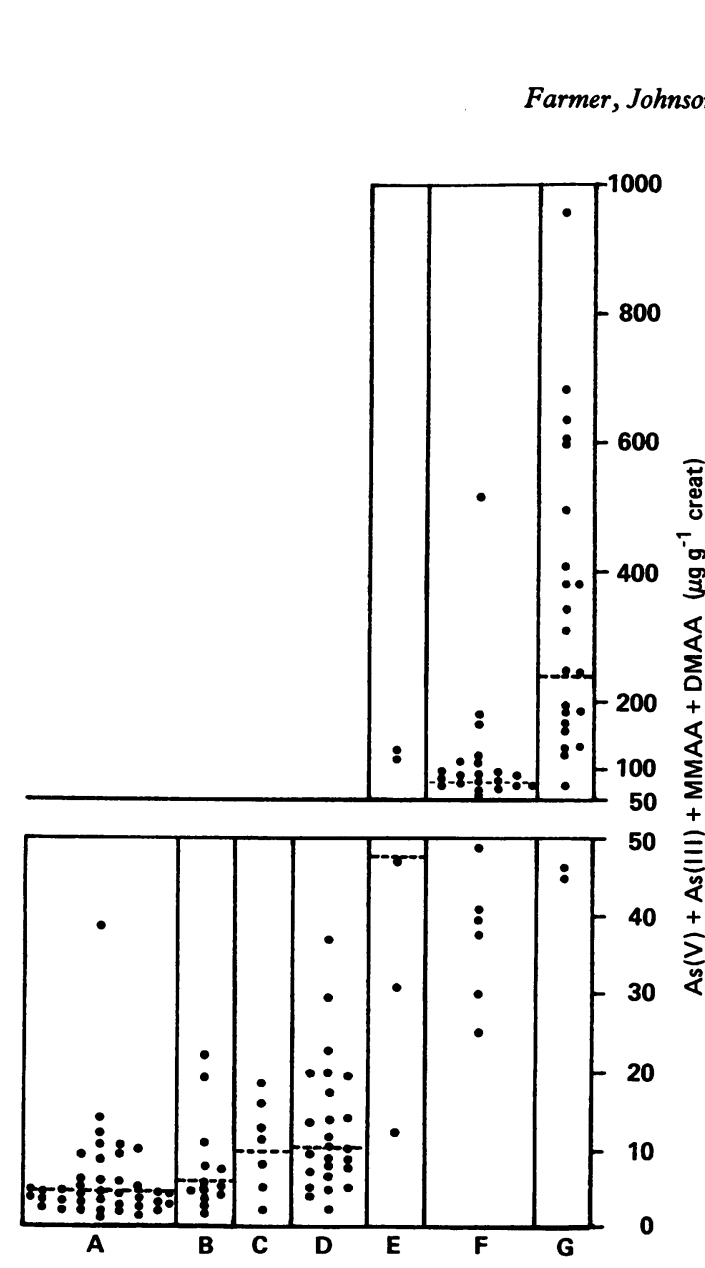

range of urinary arsenic concentrations. The ability of these techniques to distinguish between occupational exposure to inorganic arsenic and dietary exposure to inert organoarsenicals in seafood is evident in several samples, notably Nos $1,3,5,6,7$, 9 and 12. When exposure to inorganic arsenic is raised but seafood consumption is low, the total concentration of arsenic approximates well to the sum of species concentration-for instance, Nos 8, $10,11,13,14$, and 15).

Urinary sum of species (As(V), As(III), MMAA, DMAA) concentrations for workers from various occupations increased in the order controls (geom mean $4.4 \mu \mathrm{g} / \mathrm{g})<$ semiconductor $(5.9 \mu \mathrm{g} / \mathrm{g})<$ electronics $(9.7 \mu \mathrm{g} / \mathrm{g})<$ glass manufacture $(10 \cdot 2 \mu \mathrm{g} / \mathrm{g})<$ timber treatment $(47.9 \mu \mathrm{g} / \mathrm{g})<$ glass manufacture (HSE) $(79.4 \mu \mathrm{g} / \mathrm{g})<$ arsenical manufacture $(245 \mu \mathrm{g} / \mathrm{g}$ ) (figure). In much the same order of occupations, inorganic arsenic (As(V), As(III)) and the monomethylated metabolite (MMAA) became more frequently detected and achieved higher concentrations (table 2). Dimethylarsinic acid (DMAA), observed in all samples (table 2), was the major single species excreted and usually constituted considerably more than $50 \%$ of the sum but its relative importance tended to decline with increasing sum concentrations (table 3). This is illustrated in more detail for various ranges of arsenic concentrations in urine from the arsenical manufacture workers, DMAA declining from $76.0 \%(40-99 \mu \mathrm{g} / \mathrm{g})$ before levelling out at $58.2 \%(200-499 \mu \mathrm{g} / \mathrm{g})$ and $59.6 \%$ $(500-999 \mu \mathrm{g} / \mathrm{g})$. With MMAA fairly constant at $15 \cdot 6-19.0 \%$, inorganic arsenic increased from $8.3 \%$ to $22-23 \%$ over the same concentration ranges. Whereas for the controls DMAA always (40/40) exceeded $80 \%$ of the sum of species, averaging a nominal $97.6 \%$, the corresponding figures for the arsenical manufacture workers were $2 / 24(>80 \%$ ) and $63.6 \%$ (table 3 ).

Table 1 A comparison of urinary arsenic concentrations determined by direct hydride generation, analytical speciation, and total digestion methods

\begin{tabular}{lccr}
\hline Sample No & $\begin{array}{l}\text { Direct hydride } \\
\text { generation }\end{array}$ & $\begin{array}{l}\text { Sum concn } \\
(\mu g / l)\end{array}$ & Total \\
\hline 1 & $5-9$ & $5 \cdot 0$ & 441 \\
2 & $5-9$ & $5 \cdot 6$ & 34 \\
3 & $8-12$ & $8 \cdot 1$ & 430 \\
4 & $8-12$ & $10 \cdot 0$ & 24 \\
5 & $9-15$ & $12 \cdot 3$ & 159 \\
6 & $10-14$ & $15 \cdot 2$ & 2500 \\
7 & $14-22$ & $19 \cdot 7$ & 204 \\
8 & $27-44$ & $38 \cdot 6$ & 44 \\
9 & $44-63$ & $57 \cdot 8$ & 135 \\
10 & $96-150$ & 138 & 145 \\
11 & $112-180$ & 169 & 178 \\
12 & $138-198$ & 181 & 300 \\
13 & $410-580$ & 530 & 610 \\
14 & $640-1020$ & 967 & 1150 \\
15 & $860-1380$ & 1291 & 1450 \\
\hline
\end{tabular}

* Sum concentration $\equiv \Sigma$ As(V), As(III), MMAA, DMAA.

Sum of arsenic species ( $A s(V), A s$ (III), MMAA, $D M A A$ ) concentrations ( $\mu \mathrm{g} / \mathrm{g}$ creatinine) in urine of Glasgow controls $(A)$ and of workers engaged in semiconductor manufacture $(B)$, electronics research $(C)$, glass manufacture (D), timber treatment (E), glass manufacture-HSE $(F)$, and arsenical manufacture $(G)$. Geometric mean for each data set is shown by broken line (----).

\section{Discussion}

For occupationally exposed groups of workers, there have been only a few studies, based on urine analysis, $N$ that have differentiated between inorganic arsenic $+N$ methylated metabolites and total arsenic, including $N$ dietary organoarsenicals (table 4). Although the $\omega$ nature of this information is inconsistent with respect to concentration units, calculation of average concen- $\stackrel{O}{\tau}$ tration and speciation pattern detail, the pronounced $\Phi$ presence of inorganic arsenic $(9-35.8 \%)$, despite the predominance of methylated species $(64 \cdot 1-91 \%)$ with DMAA $(54.5-78 \%)$ as the major species throughout, and raised sum concentrations are similar to the findings of this study (tables 2 and 3 , figure). As with arsenical manufacture workers in this study, greater exposure to inorganic arsenic is 8 marked by a decline in the relative contribution of 
Table 2 Maximum concentration (and frequency of detection) of individual arsenic species in urine from various groups of workers

\begin{tabular}{lccccc}
\hline & & $A s(V)$ & $A s(I I I)$ & $M M A A$ & $D M A A$ \\
\cline { 5 - 6 } Category & $N o$ & & & & \\
\hline Glasgow controls & 40 & $<0 \cdot 5 \star(0)$ & $1 \cdot 0(5)$ & $0 \cdot 6(4)$ & $39 \cdot 0(40)$ \\
Semiconductor manufacture & 14 & $2 \cdot 8(1)$ & $2 \cdot 0(1)$ & $1 \cdot 4(2)$ & $22 \cdot 2(14)$ \\
Electronics research & 7 & $2 \cdot 0(3)$ & $3 \cdot 4(4)$ & $2 \cdot 4(4)$ & $13 \cdot 1(7)$ \\
Glass manufacture & 30 & $3 \cdot 8(2)$ & $12 \cdot 1(26)$ & $6 \cdot 2(24)$ & $27 \cdot 1(30)$ \\
Timber treatment & 5 & $6 \cdot 7(3)$ & $20 \cdot 9(5)$ & $21 \cdot 3(4)$ & $80 \cdot 7(5)$ \\
Glass manufacture (HSE) & 28 & $12 \cdot 2(21)$ & $54 \cdot 7(26)$ & $146(28)$ & $304(28)$ \\
Arsenical manufacture & 24 & $185(22)$ & $187(24)$ & $190(24)$ & $540(24)$ \\
\hline
\end{tabular}

^Detection limit $0.5 \mu \mathrm{g} / 1$.

Creatinine concentrations were not available for one semiconductor manufacture worker, five glass manufacture workers, and one glass manufacture (HSE) worker.

DMAA during or immediately after working hours (table 4). ${ }^{25} 29$

The predominance of methylated species-that is, MMAA + DMAA - in urine (table 3) is consistent with the natural mechanism for detoxification of inorganic arsenic via the reduction/methylation sequence $\mathrm{As}(\mathrm{V}) \longrightarrow \mathrm{As}(\mathrm{III}) \longrightarrow>\mathrm{MMAA} \longrightarrow$ DMAA.$^{89}$ The decline in the relative contribution of the methylated species, and of DMAA in particular, with increasing sum concentration is consistent with the observation from acute intoxication investigations and controlled metabolic studies that with increasing dose of inorganic arsenic the methylation efficiency decreases, perhaps as a consequence of approaching or exceeding the body's methylation capacity. ${ }^{30}$ More specifically, the conversion of MMAA to DMAA can be inhibited by high concentrations of $\mathrm{As}(\mathrm{III})$ in the liver, where methylation is believed to take place. ${ }^{911}$

Although excretion via the kidney is by far the major route of elimination of arsenic from the body, the relation of urinary arsenic concentrations to actual occupational exposure to, intake and uptake of inorganic arsenic, and the assessment of their significance with respect to health and recommended exposure limits are not straightforward. The absorption of inorganic arsenic via ingestion, inhalation, and percutaneous routes of intake may depend on factors such as chemical form, solubility, and particle size and less quantifiable parameters such as hand to mouth transfer, particle retention in lungs, and mucociliary clearance from the upper respiratory tract to the gastrointestinal tract. ${ }^{57132332}$ Best estimates of absorption range from $80 \%$ to $100 \%$ of intake via the gastrointestinal tract but only $20-30 \%$ from the lungs, largely because of the low $(\sim 35 \%)$ retention factor for particles in the lung. ${ }^{1333}$ Unfortunately, the most authoritative recommended limits for the intake of arsenic are based largely on the ingestion of readily soluble inorganic arsenic compounds (or inorganic arsenic already in solution), a situation clearly not directly extrapolable to the most common types and routes of occupational exposure, which usually include both inhalation and ingestion of airborne particles. None the less, it is instructive, as a first measure, to derive inorganic intakes based on the urinary output of inorganic arsenic and its metabolites, assuming efficient absorption (as occurs with ingestion) and using an experimentally determined relation between intake and output. On the basis of metabolic studies involving regular, repeated oral ingestion of inorganic arsenic in solution by volunteers, it has been shown, both in this laboratory (L R Johnson, J G Farmer, unpublished data) and

Table 3 The relative mean proportions ${ }^{\star}$ of the individual arsenic species excreted in urine by various groups of workers

\begin{tabular}{|c|c|c|c|c|c|c|c|c|}
\hline \multirow[b]{2}{*}{ Category } & \multirow{2}{*}{$\begin{array}{l}\text { Sum concn } \\
\text { range }(\mu g / g)\end{array}$} & \multirow[b]{2}{*}{ No } & $A s(V)$ & $A s(I I I)$ & $M M A A$ & $D M A A$ & Inorganic & Methylated \\
\hline & & & \multicolumn{6}{|l|}{$\left(\begin{array}{l}o \\
0\end{array}\right)$} \\
\hline $\begin{array}{l}\text { Controls } \\
\text { Semiconductor } \\
\text { Electronics } \\
\text { Glass } \\
\text { Timber } \\
\text { Glass (HSE) } \\
\text { Arsenical }\end{array}$ & $\begin{array}{c}1 \cdot 2-39 \cdot 0 \\
1 \cdot 7-22 \cdot 2 \\
4 \cdot 6-18 \cdot 6 \\
2 \cdot 0-37 \cdot 2 \\
12 \cdot 3-126 \\
25 \cdot 3-517 \\
45 \cdot 2-956 \\
40-99 \\
100-199 \\
200-499 \\
500-999\end{array}$ & $\begin{array}{r}40 \\
14 \\
7 \\
30 \\
5 \\
28 \\
24 \\
3 \\
8 \\
8 \\
5\end{array}$ & $\begin{array}{l}0 \\
1 \cdot 0 \\
8 \cdot 9 \\
0 \cdot 9 \\
4 \cdot 6 \\
2 \cdot 3 \\
6 \cdot 1 \\
0 \cdot 4 \\
3 \cdot 6 \\
9 \cdot 4 \\
8 \cdot 3\end{array}$ & $\begin{array}{r}1 \cdot 7 \\
0 \cdot 8 \\
7 \cdot 7 \\
14 \cdot 0 \\
14 \cdot 2 \\
11 \cdot 3 \\
12 \cdot 1 \\
7 \cdot 9 \\
11 \cdot 3 \\
13 \cdot 5 \\
13 \cdot 7\end{array}$ & $\begin{array}{r}0.7 \\
1.5 \\
8 \cdot 0 \\
15 \cdot 4 \\
13.9 \\
17 \cdot 8 \\
18 \cdot 2 \\
15 \cdot 6 \\
18 \cdot 4 \\
19 \cdot 0 \\
18 \cdot 4\end{array}$ & $\begin{array}{l}97 \cdot 6 \\
96 \cdot 7 \\
75 \cdot 4 \\
69 \cdot 7 \\
67 \cdot 4 \\
68 \cdot 7 \\
63 \cdot 6 \\
76 \cdot 0 \\
66 \cdot 8 \\
58 \cdot 2 \\
59 \cdot 6\end{array}$ & $\begin{array}{r}1 \cdot 7 \\
1.8 \\
16 \cdot 6 \\
14 \cdot 9 \\
18 \cdot 8 \\
13 \cdot 6 \\
18 \cdot 2 \\
8 \cdot 3 \\
14 \cdot 9 \\
22 \cdot 9 \\
22 \cdot 0\end{array}$ & $\begin{array}{l}98 \cdot 3 \\
98 \cdot 2 \\
83 \cdot 4 \\
85 \cdot 1 \\
81 \cdot 3 \\
86 \cdot 5 \\
81 \cdot 8 \\
91 \cdot 6 \\
85 \cdot 2 \\
77 \cdot 2 \\
78 \cdot 0\end{array}$ \\
\hline
\end{tabular}

*Where individual arsenic species were not detected-that is, $<0.5 \mu \mathrm{g} / 1$ - their concentration was taken as $0 \mu \mathrm{g} / 1$ and, therefore, $0 \mu \mathrm{g} / \mathrm{g}$ creatinine. 
Table 4 Summary of published data on the sum concentrations of urinary arsenic species $(A s(V), A s(I I I), M M A A$, and $D M A A)$ excreted by workers in various industries and on the associated arsenic speciation patterns

\begin{tabular}{|c|c|c|c|c|c|c|}
\hline \multirow[b]{2}{*}{ Industry } & \multicolumn{2}{|c|}{ Sum Concn } & \multicolumn{4}{|c|}{ Speciation pattern } \\
\hline & $\underset{(\mu g / l)}{\operatorname{Maxm}}$ & Arith mean & $\begin{array}{l}A s(V) \\
(\%)\end{array}$ & $A s(I I I)$ & $M M A A$ & $D M A A$ \\
\hline Glass manufacture ${ }^{1223}$ & $941^{\star}$ & $\begin{array}{c}81 \cdot 2 \\
304^{\star}\end{array}$ & & & $16 \cdot 9$ & $61 \cdot 6$ \\
\hline $\begin{array}{l}\text { Pesticides: } \\
\text { Mixing } \\
\text { Spraying }^{24}\end{array}$ & $\begin{array}{l}654 \\
269\end{array}$ & $\begin{array}{r}227 \\
83\end{array}$ & & & $\begin{array}{l}23 \\
20\end{array}$ & $\begin{array}{l}67 \\
62\end{array}$ \\
\hline $\begin{array}{l}\text { Arsenical manufacture }{ }^{25} \text { : } \\
\text { Before work } \\
\text { After work } \\
\text { Smelting }^{26-285} \text { : }\end{array}$ & $\begin{array}{l}273 \\
340 \\
580 \\
328^{\star}\end{array}$ & $\begin{array}{c}135 \cdot 1 \\
158 \cdot 9 \\
96 \cdot 6 \dagger \\
70 \\
61 \\
79 \star \dagger\end{array}$ & $\begin{array}{r}13 \cdot 4 \\
16 \cdot 9 \\
3 \cdot 2\end{array}$ & $\begin{array}{r}15 \cdot 3 \\
18 \cdot 9 \\
8 \cdot 9\end{array}$ & $\begin{array}{r}10 \cdot 7 \\
9 \cdot 6 \\
21 \cdot 5\end{array}$ & $\begin{array}{l}60 \cdot 6 \\
54 \cdot 5 \\
66 \cdot 4\end{array}$ \\
\hline $\begin{array}{l}\text { Continuous }^{29} \\
\text { After weekend }^{29}\end{array}$ & $\begin{array}{l}300 \dagger \\
140 \dagger\end{array}$ & & & & $\begin{array}{l}20 \\
13\end{array}$ & $\begin{array}{l}61 \\
78\end{array}$ \\
\hline
\end{tabular}

elsewhere, ${ }^{30}$ that $40-60 \%$ of the daily intake of inorganic arsenic is excreted each day in urine, once equilibrium between intake and output is established-usually about one to five days after the start of intake for intakes increasing to $1000 \mu \mathrm{g} /$ day. Confidence in applying this relation to the case of workers exposed to atmospheric particulate arsenic is provided by the observation ${ }^{5}$ that the average daily urinary excretion of arsenic by smelter workers was $42 \%$ of the inhaled amount derived from direct measurements of airborne inorganic arsenic.

The WHO recommend a provisional maximum tolerable daily intake of ingested inorganic arsenic of $2 \mu \mathrm{g} / \mathrm{kg}$ body weight. ${ }^{34}$ For a $70 \mathrm{~kg}$ man this is equal to a provisional tolerable daily intake of $140 \mu \mathrm{g}$ inorganic arsenic. This corresponds to an output of 56-84 $\mu \mathrm{g}$ arsenic based on an output of $40-60 \%$ of the intake. Assuming that an average $1.5 \mathrm{~g}$ creatinine-that is, 1.51 urine with a concentration of $1 \mathrm{~g} / 1^{18}$-is excreted daily, this gives a urinary arsenic concentration of $37-56 \mu \mathrm{g} / \mathrm{g}$ creatinine. Similarly, the daily intake of $150 \mu \mathrm{g}$ inorganic arsenic (equivalent to drinking $1.5 \mathrm{l}$ water with an average concentration of arsenic of $0.1 \mathrm{mg} / 1$ ), considered by the Committee on the Toxicity of Chemicals in Food, Consumer Products and the Environment (COT) $)^{35}$ to give rise to "presumptive toxicity," corresponds to a urinary arsenic concentration of $40-60 \mu \mathrm{g} / \mathrm{g}$. With one exception, the controls are well below this level (figure); indeed, the geometric mean concentration of $4.4 \mu \mathrm{g} / \mathrm{g}$ corresponds to a calculated daily intake of inorganic arsenic of $11.0-16.5 \mu \mathrm{g} / \mathrm{g}$, comparable with the estimate of $22 \mu \mathrm{g} /$ day which may be derived from the $M A F F^{10}$ value for the average dietary intake of total arsenic of $89 \mu \mathrm{g} / \mathrm{d}$ to which seafood contributes $75 \%$, almost all in the form of inert organoarsenicals. Of the workers in the various occupationally exposed groups (figure), two of five in group E (timber treatment), 20 of 27 in group F (glass manufactureHSE), and 22 of 24 in group G (arsenical manufacture) exceeded the upper level of $60 \mu \mathrm{g} / \mathrm{g}$.

Largely on the basis of epidemiological evidence? linking inorganic arsenic exposure, via consumption of drinking water of raised arsenic concentration, to a range of diseases in certain parts of the world, COT also reported that a daily intake of $1500 \mu \mathrm{g}$ inorganic arsenic (equivalent to drinking 1.51 water with an $\underset{\mathbb{D}}{\mathbb{2}}$ inorganic arsenic concentration of $1 \mathrm{mg} / \mathrm{l}$ ) could $\underset{\vec{P}}{\vec{A}}$ produce signs of "overt chronic arsenicism" in some individuals. ${ }^{35}$ This corresponds to a daily output of 600-900 $\mu \mathrm{g}$ arsenic and gives a urinary arsenic concentration of $400-600 \mu \mathrm{g} / \mathrm{g}$. In group G (arsenical manufacture) five of the urine samples exceeded $600 \mu \mathrm{g} / \mathrm{g}$, with seven of this group and one of group $\mathrm{F}$ (glass manufacture-HSE) higher than $400 \mu \mathrm{g} / \mathrm{g}$ (figure). The maximum urinary arsenic concentration for group $\mathrm{G}$ was $956 \mu \mathrm{g} / \mathrm{g}$, which is equivalent to an intake of 2390-3585 $\mu$ g inorganic arsenic a day, far in excess of the WHO and COT recommended limits. ${ }^{3435}$ It is worth noting that if absorption of $\frac{7}{2}$ inorganic arsenic by the bodies of these occupationally exposed workers is not $100 \%$ efficient, then the $N$ derived intakes may underestimate the actual combined intake via inhalation and ingestion. Although the extent of uptake, rather than intake, is clearly of $\omega$ greater significance with respect to health, recommended limits of exposure are often set in terms- $O$ for instance, $\mu \mathrm{g} / 1$ water, $\mu \mathrm{g} / \mathrm{m}^{3}$ air $^{1013}{ }^{135-37}$ that serve $\mathbb{D}$ as reference benchmarks against which ambient environmental or workplace arsenic concentrations may be directly compared.

A few studies, based largely on smelter workers, have attempted to quantify possible correlations between the levels of airborne arsenic and the concentrations of urinary arsenic. Vahter et al found that urinary concentrations $(\mathrm{As}(\mathrm{V}), \mathrm{As}(\mathrm{III})$, 
MMAA, DMAA) of 50-200 $\mu \mathrm{g} / 1$ were equivalent to airborne As levels of $1.7-53 \mu \mathrm{g} / \mathrm{m}^{3},{ }^{5}$ with a best fit empirically established linear relation

$$
\mathrm{As}_{\mathrm{urinc}}(\mu \mathrm{g} / \mathrm{l})=45+2.9 \mathrm{As}_{\text {air }}\left(\mu \mathrm{g} / \mathrm{m}^{3}\right)
$$

$$
\text { that is, } \mathrm{As}_{\text {air }}\left(\mu \mathrm{g} / \mathrm{m}^{3}\right)=0.345 \mathrm{As}_{\text {urine }}(\mu \mathrm{g} / \mathrm{l})-15.5
$$

Insertion of the threshold $60 \mu \mathrm{g} / \mathrm{g}$ and $600 \mu \mathrm{g} / \mathrm{g}$ concentrations derived from $\mathrm{COT}^{35}$ arsenic exposure considerations into the above equations (assuming a creatinine concentration of $1 \mathrm{~g} / \mathrm{l}$ ) yields airborne arsenic concentrations of $5.2 \mu \mathrm{g} / \mathrm{m}^{3}$ and $191 \mu \mathrm{g} / \mathrm{m}^{3}$, the latter being close to the former Health and Safety Executive $^{36}$ eight hour time weighted average control limit of $200 \mu \mathrm{g} / \mathrm{m}^{3}$, reduced ${ }^{37}$ since 1 January 1989 to $100 \mu \mathrm{g} / \mathrm{m}^{3}$. This corresponds to a urinary arsenic concentration of $335 \mu \mathrm{g} / \mathrm{g}$, exceeded by one of 27 in group F (glass manufacture-HSE) and 10 of 24 in group $\mathrm{G}$ (arsenical manufacture).

The use of atmospheric/urinary arsenic correlations and extrapolations in evaluating health risks, especially the contraction of lung cancer, ${ }^{6}$ should be viewed with caution. ${ }^{13}$ Both Vahter $e t$ al and Roels $e t$ al have shown the potential importance of the direct oral ingestion route for some employees in workplaces such as glassworks and smelters where inhalation and absorption of airborne arsenic via the lungs might be expected to predominate. ${ }^{58}$ The critical effect following the latter exposure route is lung cancer whereas several effects, such as skin cancer, are more likely after oral exposure. Such considerations, however, actually reinforce the need for biological markers of exposure-for example, urine-as opposed to external markers of exposure, such as airborne arsenic, which can provide an estimate of exposure via one route only-namely, inhalation. The determination of arsenic (inorganic arsenic + metabolites) in urine, on the other hand, provides an estimate of total exposure and is also more relevant to an assessment of the exposure of each individual worker.

We have attempted to show the importance of urinary arsenic determination in the monitoring and assessment of occupational exposure to inorganic arsenic. In particular, the separation of inorganic arsenic and its metabolites from dietary organoarsenicals is essential. Detailed analytical speciation of urinary arsenic into As(V), As (III), MMAA, and DMAA is the most reliable way to measure $\Sigma A s(V)$, As(III), MMAA, DMAA and may be of additional value in investigating the chemical nature $(\mathrm{As}(\mathrm{V})$ or $\mathrm{As}(\mathrm{III})$ ) and duration of exposure to arsenic, as well as the status of the body's detoxifying methylation capacity. A rapid alternative for screening purposes is direct hydride generation from acidified urine for estimation of the sum of the four hydride forming species by AAS. The range of data obtained in this study for individuals occupationally exposed to inorganic arsenic in the United Kingdom shows the need for vigilance and regular monitoring of urinary arsenic by methods of adequate sophistication.

We thank those organisations and individuals, too numerous to detail, who provided urine samples and, in addition, Messrs $\mathrm{N} \mathrm{J}$ Smith and B S Chana of the Health and Safety Executive, London, for their cooperation in the intercomparison exercises. Dr T D B Lyon, Department of Biochemistry, Glasgow Royal Infirmary, supplied the urinary creatinine data. We gratefully acknowledge the partial financial support of LRJ's research studentship by NERC.

1 Kipling MD. Arsenic. In: Lenihan J, Fletcher WW, eds. The chemical environment, environment and man. Vol 6. Glasgow: Blackie, 1977:93-120.

2 World Health Organisation. Environmental health criteria 18: arsenic. Geneva: World Health Organisation, 1981.

3 Health and Safety Executive. Toxicity review 16: inorganic arsenic compounds. London: HMSO, 1986.

4 Pershagen $\mathrm{G}$. The epidemiology of human arsenic exposure. In: Fowler BA, ed. Biological and environmental effects of arsenic. Amsterdam: Elsevier, 1983:199-233.

5 Vahter M, Friberg L, Rahnster B, Nygren Å, Nolinder P. Airborne arsenic and urinary excretion of metabolites of inorganic arsenic among smelter workers. Int Arch Occup Environ Health 1986;57:79-91.

6 Enterline PE, Henderson VL, Marsh GM. Exposure to arsenic and respiratory cancer. Am J Epidemiol 1987;125:929-38.

7 Buchet JP, Lauwerys R, Roels $\mathrm{H}$. Comparison of several methods for the determination of arsenic compounds in water and in urine. Their application for the study of arsenic metabolism and for the monitoring of workers exposed to arsenic. Int Arch Occup Environ Health 1980;46:11-29.

8 Vahter M. Metabolism of arsenic. In: Fowler BA, ed. Biological and environmental effects of arsenic. Amsterdam: Elsevier, 1983:171-98.

9 Vahter $M$, Marafante $E$. In vivo methylation and detoxication of arsenic. In: Glockling F, Craig PJ, eds. The biological alkylation of heavy elements. London: Royal Society of Chemistry, 1988:105-19. (Spec publ No 66.)

10 Ministry of Agriculture, Fisheries and Food. Survey of arsenic in food. London: HMSO, 1982. (Food surveillance paper No 8.)

11 Buchet JP, Lauwerys R. Evaluation of exposure to inorganic arsenic in man. In: Facchetti S, ed. Analytical techniques for heavy metals in biological fluids. Amsterdam: Elsevier, 1983:75-90.

12 Foa V, Colombi A, Maroni M, Buratti M, Calzaferri G. The speciation of the chemical forms of arsenic in the biological monitoring of exposure to inorganic arsenic. Sci Total Environ 1984;34:241-59.

13 Zielhuis RL, Wibowo AAE. Standard setting and metal speciation: arsenic. In: Nriagu JO, ed. Changing metal cycles and human health. Berlin: Springer-Verlag, 1984:323-44.

14 Ungers LJ, Jones JH, McIntyre AJ, McHenry CR. Release of arsenic from semiconductor wafers. Am Ind $\mathrm{Hyg}$ Assoc $J 1985 ; 46: 416-20$.

15 Johnson LR, Farmer JG. Urinary arsenic concentrations and speciation in Cornwall residents. Environmental Geochemistry and Health 1989;11:39-44.

16 Grabinski AA. Determination of arsenic (III), arsenic (V), monomethylarsonate and dimethylarsinate by ion-exchange chromatography with flameless atomic absorption spectrometric detection. Anal Chem 1981;53:966-8.

17 Lovell MA, Farmer JG. Arsenic speciation in urine from humans intoxicated by inorganic arsenic compounds. Human Toxicol 1985;4:203-14.

18 Johnson LR. The chemical speciation and transformations of arsenic in humans and in the environment. Glasgow: University of Glasgow, 1986. (PhD thesis.)

19 Chana BS, Smith NJ. Urinary arsenic speciation by highperformance liquid chromatography/atomic absorption spectrometry for monitoring occupational exposure to inorganic arsenic. Analytica Chimica Acta 1987;197:177-86.

20 Hinners TA. Arsenic speciation: limitations with direct hydride 
analysis. Analyst 1980;105:751-5.

21 Sinemus $\mathrm{HW}$, Melcher M, Welz B. Influence of valence state on the determination of antimony, arsenic, bismuth, selenium and tellurium in lake water using the hydride technique. Atomic Spectroscopy 1981;2:81-6.

22 Norin $H$, Vahter $M$. A rapid method for the selective analysis of total urinary metabolites of inorganic arsenic. Scand $J W$ ork Environ Health 1981;7:38-44.

23 Roels H, Buchet JP, Truc J, Croquet F, Lauwerys R. The possible role of direct ingestion on the overall absorption of cadmium or arsenic in workers exposed to $\mathrm{CdO}$ or $\mathrm{As}_{2} \mathrm{O}_{3}$ dust. Am J Ind Med 1982;3:53-65.

24 Wojeck GA, Nigg HN, Braman RS, Stamper JH, Rouseff RL. Worker exposure to arsenic in Florida grapefruit spray operations. Arch Environ Contam Toxicol 1982;11:661-7.

25 Yamamura Y, Yamauchi $\mathbf{H}$. Arsenic metabolites in hair, blood and urine in workers exposed to arsenic trioxide. Industrial Health 1980;18:203-10.

26 Smith TJ, Crecelius EA, Reading JC. Airborne arsenic exposure and excretion of methylated arsenic compounds. Environ Health Perspect 1977;19:89-93.

27 Lagerkvist B, Linderholm H, Nordberg GF. Vasospastic tendency and Raynaud's phenomenon in smelter workers exposed to arsenic. Environ Res 1986;39:465-74.

28 Lagerkvist BEA, Linderholm H, Nordberg GF. Arsenic and Raynaud's phenomenon. Vasospastic tendency and excretion of arsenic in smelter workers before and after the summer vacation. Int Arch Occup Environ Health 1988;60:361-4.

29 Vahter $M$. Environmental and occupational exposure to in- $\overrightarrow{\vec{C}}$ organic arsenic. Acta Pharmacol Toxicol 1986;59:31-4.

30 Buchet JP, Lauwerys R, Roels H. Urinary excretion of inorganic $\bar{C}$ arsenic and its metabolites after repeated ingestion of sodium $\frac{}{5}$ meta-arsenite by volunteers. Int Arch Occup Environ Health 1981;48:111-8.

31 Buchet JP, Lauwerys R. Study of inorganic arsenic methylation $\mathbb{\Phi}$ by rat liver in vitro: relevance for the interpretation of 2 observations in man. Arch Toxicol 1985;57:125-9.

32 Pershagen G, Lind B, Björklund N-E. Lung retention and toxicity of some inorganic arsenic compounds. Environ Res $\overrightarrow{0}$ 1982;29:425-34.

33 Bennett BG. Exposure of man to environmental arsenic-an $\overrightarrow{\vec{c}}$ exposure commitment assessment. Sci Total Environ 1981; $\omega$ 20:99-107.

34 World Health Organisation. 27th Report of the joint FAO/WHO expert committee on food additives. Geneva: WHO, 1983:29. (Tech rep series 696.)

35 Ministry of Agriculture, Fisheries and Food. Food additives and \pm contaminants committee report on the review of the arsenic in food ir regulations, $F A C / R E P / 39$. London: HMSO, 1984.

36 Health and Safety Executive. Arsenic: toxic hazards and precautions. London: HMSO, 1987. (Guidance note EH8.)

37 Arsenic controls. Chemistry in Britain 1989;25:125.

Accepted 25 September 1989 